\title{
Antioxidant Capacity of Dark Red Corn - Biochemical Properties Coupled with Electrochemical Evaluation
}

\author{
MAJA STEVANOVIC ${ }^{1}$, SANJA STEVANOVIC ${ }^{2}$, MARIJA MIHAILOVIC ${ }^{2}$, \\ BILJANA KIPROVSKI ${ }^{3}$, GORAN BEKAVAC ${ }^{3}$, MAJA MIKULIC-PETKOVSEK ${ }^{4}$, \\ JELENA LOVIC ${ }^{2 *}$ \\ ${ }^{1}$ Innovation Centre of the Faculty of Technology and Metallurgy, University of Belgrade, Karnegijeva 4, Belgrade, Serbia \\ ${ }^{2}$ Institute of Chemistry, Technology and Metallurgy, University of Belgrade, Department of Electrochemistry, Njegoševa \\ 12, 11000 Belgrade, Serbia \\ ${ }^{3}$ Institute of Field and Vegetable Crops, Maksima Gorkog 30, 21000 Novi Sad, Serbia \\ ${ }^{4}$ Biotechnical faculty, Department of Agronomy, University of Ljubljana, Jamnikarjeva 101, 1000 Ljubljana, Slovenia
}

\begin{abstract}
Biochemistry coupled with electrochemical approach is employed in a fast, relatively simple, yet highly precise detection of a plant extract antioxidant properties. Antioxidant capacity of dark red corn grains was investigated electrochemically using cyclic voltammetry $(C V)$ on glassy carbon electrode $(G C)$. The linear polarization resistance (LPR) measurements were performed for examining the corrosion inhibitive behavior of polyphenolics on mild steel. The consistent positive correlation $(r=0.99)$ was established between total phenolic and flavonoid contents obtained by $C V$ measurements and spectrophotometric antioxidant assay (DPPH test). Both analyses confirm the high antioxidant activity of tested pigments. Determination of the corrosion inhibition efficiency revealed that the red corn pigments have anti-corrosion effect on mild steels.
\end{abstract}

Keywords: antioxidant activity, voltammetry, linear polarization resistance, corrosion inhibitor

\section{Introduction}

Polyphenols which include a number of subgroups of phenolic compounds represent one of the largest families of antioxidants [1]. Polyphenols are mainly correlated with carotenoids, ascorbic acid, caffeic acid, gallic acids [2, 3]. The beneficial effect of polyphenols regarding their antioxidant properties is well documented in the literature. The antioxidant capacity detection of polyphenolic compounds is usually based on electrochemical, spectroscopic, chromatographic or some other technique $[2,4]$. Žilić et. al examined ten different colored maize genotypes from the aspect of phenolic compounds, carotenoids, and antioxidant capacity [5]. Based on the results of total anthocyanin contents they indicated that some of the colored maize kernels such as dark red, dark blue, and light blue maize may have potential in the improvement of the development of natural colorants. The antioxidant capacity of four maize varieties characterized by the kernel colors ranging from orange to red and dark red have been determined by means of spectrophotometric antioxidant assays showing that the red/dark red maize have greater antioxidant capacity [6].

The application of electrochemical methods to antioxidant capacity determination is based on fact that antioxidant, i.e. free radical reactions involve the electron transfers who enable fast electrochemical screening of a large numbers of organic compounds even in complex or coloured samples [2,3]. Cycling voltammetry examinations includes detection of oxidation-reduction activity of examined samples by recording of the current intensity while varying of potential with time and the antioxidant molecules will give voltammetric peaks on the current intensity axis. Integrating the surface below the peak will yield the antioxidant capacity of these compounds. Literature data showed that cyclic voltammetry at glassy carbon working electrode allowed the characterization of a wide range of compounds such as phenolic acids and flavonoids. The antioxidant activity of these pigments (flavonoids) can be evaluated using different free radical generators [7-10]. For example, phenolic

*email: jelena.lovic@ihtm.bg.ac.rs 
groups of flavonoids can be electrochemically oxidized (most flavonoids will show an oxidation peak) and based on the values of the potentials at which the maximum oxidation is achieved [11] and the current intensity below the current peak, the antioxidant capacity of these compounds can be determined. In a recent electrochemical study, several anthocyanins were determined by cyclic and differential pulse voltammetry $[12,13]$. It was shown that antioxidant activity of those compounds, based on redox potentials, is in a very good agreement with results evaluated by a radical scavenging method [12]. This antioxidant activity of polyphenolics was accompanied with the corrosion inhibiting examination, since the most of the green corrosion inhibitors are recently found in the group of these organic molecules $[14,15]$. The quest for green inhibitors started with the awareness of widely used inhibitors toxicity to humans and environment and the fact the best acid inhibitors are organic compounds containing N, P, O and S which can donate lone pairs of electrons. Extracts of plants such as Rosmarinus officinalis L, Lawsonia inermis, Punica granatum, but also their constituents such as vitamin C, tannins, gallic acid and so on were confirmed to have corrosion inhibitive effect [16 - 18].

In order to establish a fast, sensitive and simple instrumental procedure without the demanding pretreatment of samples, in addition to traditional techniques, this paper aimed to use electrochemical techniques to determine the antioxidant capacity of dark red corn grains using CV to analyse the voltammetric behaviour of a red corn bioactive compounds and the LPR measurements to examine the corrosion inhibitive behaviour of polyphenolics on mild steel.

\section{Materials and methods Plant material}

Dark red corn (Zea mays L.) used in the study originates from Central America. Three cycles of family selection for adaptation were conducted in each of four local populations of dark red corn. The main criterions were earliness and tolerance to diseases. Equal seed quantity, from each population, was then bulked and randomly mated in 2015 to produce NS-RB 01 population. The S1 progenies were developed in 2016 breeding nursery by selfing of S0 plants. At the harvest, 100 ears were randomly chosen bearing in mind seed quantity for trials and selfing. Among these, several samples were selected for the chemical analysis, and the main criterion was colour of the grain and the phenotype of the S1 progeny. Grains of the selected population were tested for total sugars and carotenoids, as well as total and individual polyphenolic compounds. Additionally, aqueous extracts of these grains were tested for their potential antioxidant properties using biochemical and electrochemical methods.

\section{Biochemical properties}

Total sugars, carotenoids, polyphenolic compounds were determined in tested dry dark red corn grains (approx. 8\% moisture content). Total sugars were determined according to Luff-Schoorl method (AACC 80-60.01) [19].

Total carotenoids content was determined according to slightly modified method reported by de Carvalho et al. [20]. Milled grains (10 g) was homogenized in a chilled mortar, under the dim light and placed into tubes $(50 \mathrm{~mL})$ with cold acetone $(6 \mathrm{~mL})$ and petroleum ether $(3 \mathrm{~mL})$. After covering with aluminium foil, $1 \mathrm{~h}$ extraction (in a cooled ultrasonic bath) and $10 \mathrm{~min}$ centrifugation (at $12.857 \mathrm{~g}$ ), absorbance of the petroleum ether phase (additionally diluted with a petroleum ether) was recorded on the spectrophotometer $(\lambda=450 \mathrm{~nm})$. Total carotenoid content was expressed as $\beta$-carotene equivalents in $\mathrm{mg} \mathrm{g}^{-1}$ dry weight $(\mathrm{dw})$.

\section{Determination of total phenolic content}

Milled dark red corn kernels $(0.5 \mathrm{~g})$ were extracted in a cooled ultrasonic bath $(1 \mathrm{~h})$ with $70 \%$ methanol $(10 \mathrm{~mL})$ containing $3 \%(\mathrm{v} / \mathrm{v})$ formic acid. After centrifugation $(10 \mathrm{~min})$ at $10669 \mathrm{~g}$, extracts were filtered through the Chromafil AO-20/25 polyamide filter (Macherey-Nagel, Düren, Germany) and analysed further (MeOH extract). 
Total polyphenolic (TPC) and total tannin contents of methanolic extract was determined by FolinCiocalteau phenol reagent method [21]. All results were expressed as gallic acid equivalents (GAE) in $\mathrm{mg} \mathrm{g}^{-1} \mathrm{dw}$. Determination of total flavonoids and anthocyanin contents in methanolic extract was performed according to Pękal and Pyrzynska [22] and Lee et al. [23], respectively, and slightly modified as it was explained in Kiprovski et al. [24]. Total flavonoids content was expressed as mg rutin $\mathrm{mg} \mathrm{g}^{-1} \mathrm{dw}$ and total monomeric anthocyanin content was expressed as $\mathrm{mg}$ cyanidin-3-O-glucoside equivalents $\mathrm{g}^{-1} \mathrm{dw}$.

\section{Antioxidant capacity (scavenging) tests}

Aqueous extract of milled dark red corn kernels $(50 \mathrm{~g})$ was prepared in $1 \mathrm{~L}$ of distilled water in simmering water bath for $1 \mathrm{~h}$. The aqueous extracts were centrifuged $(10 \mathrm{~min})$ at $10669 \mathrm{~g}$ and supernatant was used in further analysis, along with $\mathrm{MeOH}$ extract used for contents of total polyphenolic compounds. Total potential antioxidant activity of investigated methanolic and aqueous extracts was tested based on their scavenging of 1.1-diphenyl-2-picrylhydrazyl (DPPH) free radicals [25] and expressed as \% inhibition.

\section{Extraction and determination of individual polyphenolic compounds}

Milled dark red corn kernels $(1 \mathrm{~g})$ were extracted in a cooled ultrasonic bath (1 h) with $3 \mathrm{~mL}$ of $70 \%$ methanol containing 3\% formic acid and, to prevent oxidation, $1 \%$ 2.6-di-tert-butyl-4-methylphenol was added (BHT). After centrifugation at $10669 \mathrm{~g}(10 \mathrm{~min})$, the extracts were filtered (Chromafil AO-20/25 polyamide filter, Macherey-Nagel, Düren, Germany) and transferred to a vial. Phenolic compounds were analysed on a Thermo Finnigan Surveyor HPLC system and identified by an HPLC-Finnigan MS detector and an LCQ Deca XP MAX (Thermo Scientific, San Jose, USA) by Wang et al. [26] method slightly modified as it is explained in Kiprovski et al. [27]. Identified individual phenolics were calculated using the corresponding external standard and expressed in $\mu \mathrm{g} \mathrm{g}^{-1}$ of grain dw.

\section{Electrochemical investigations}

Voltammetric measurements were performed with a 402 Volta Lab (Radiometer Analytical, Lyon, France). The three electrode electrochemical cell with GC (surface area $0.196 \mathrm{~cm}^{2}$ ) as working electrode, platinum wire as counter electrode and saturated calomel electrode as reference one, was used. All the potentials are given vs. SCE. The electrochemical studies were performed in $0.1 \mathrm{M}$ $\mathrm{H}_{2} \mathrm{SO}_{4}$. GC electrode was prepared by mechanical treatment, which involves abrasion with emery paper, polishing with $\mathrm{Al}_{2} \mathrm{O}_{3}$ suspension (particle size $1,0.3$ and $0.05 \mu \mathrm{m}$ ) and washed with deionized water. Solutions of aqueous extract of milled dark red corn kernels used in DPPH-test were prepared by dilution of $0.25-1 \mathrm{~mL}$ of water extract in $50 \mathrm{~mL}$ of $0.1 \mathrm{M} \mathrm{H}_{2} \mathrm{SO}_{4}$ for electrochemical measurements (in further text red corn pigments).

The electrochemical corrosion measurements were carried out in a standard three-electrode cell, the reference electrode was SCE and the counter electrode was Pt-mesh, while the working electrode was made of mild steel. Measurements were performed by a GAMRY Reference 1010E Potentiostat /Galvanostat/ ZRA. Linear polarization resistance (Rp) was determined using Gamry software after measurement in the potentials range of $-0.01 \mathrm{~V}-0.01 \mathrm{~V}$ versus open circuit potential (Eoc). The active electrode surface $\left(0.785 \mathrm{~cm}^{2}\right)$ was wet polished with emery papers (grit sizes 600-800-1000-2000) before each measurement. The Rp measurements were performed in the electrolyte of $p \mathrm{H} 2$, made of $0.3 \mathrm{~mol} \mathrm{~L}^{-1} \mathrm{NaCl}$ and $0.1 \mathrm{~mol} \mathrm{~L}^{-1} \mathrm{Na}_{2} \mathrm{SO}_{4}$, without and with addition of the corn pigments in the concentration range of $0.4-2 \mathrm{mg} \mathrm{L}^{-1}$. The electrolyte was chosen so as to simulate usual atmospheric conditions. 


\section{Statistical analysis}

Values of the biochemical parameters were tested using STATISTICA for Windows version 12 (Dell Software) and expressed as means \pm standard error.

\section{Results and discussions}

\section{Electrochemical and biochemical behavior of dark red corn grains}

Electrochemical behavior of the red corn pigments was firstly examined by CV for different concentrations of aqueous extracts of dark red corn seeds, as is presented in Figure 1. CVs indicated that the electrochemical oxidation of tested compounds was presented by two peaks in forward direction and two peaks on the backward scan, indicating a quasi-reversible process. First peak was attributed to the oxidation of the polyphenolic compounds containing a flavonoid structure, while the second one was attributed to anthocyanins $[28,29]$. The explanation of the obtained electrochemical response is in accordance with the biochemical results presented in Tables 1 and 2. In addition, the observed electrochemical behavior can be attributed to the well-described path for the oxidation of phenols, hydroquinones, and derivatives [30]. No activity of pigments was observed in alkaline solution. Electrochemical behavior of some phenolic acids and flavones also exhibited no activity at $p \mathrm{H}>8.0$ [31]. Besides, it was noticed that successive scans have shown almost constant values of currents after the first scan indicating that the poisoning of the surface electrode by adsorbing species is negligible.

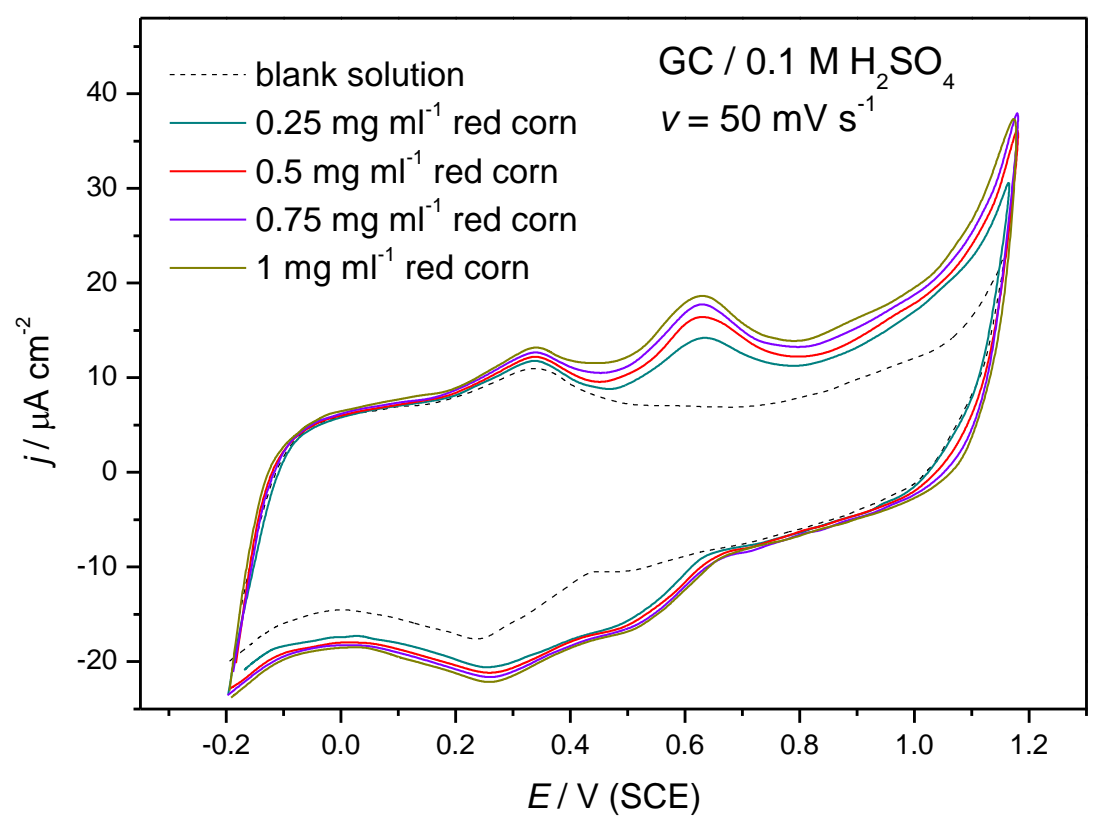

Figure 1. CVs of different concentrations of red corn pigments at GC electrode in $0.1 \mathrm{M} \mathrm{H}_{2} \mathrm{SO}_{4} ; v=50 \mathrm{mV} \mathrm{s}^{-1}$

$\mathrm{CV}$ measurements provide the sum of total antioxidants and presence of each peak is associated to different groups of phenolic compounds [31]. CV technique has been used to determine the phenolic content of wines and to correlate the analytical response to the antioxidant capacity of these wines [32]. The determination of the charge under the anodic peak was used as a measure of the quantity of antioxidants. The obtained dependency of charge in the region $-0.2-1.2 \mathrm{~V}$ on the concentration of tested red corn pigments was presented in Figure $2 \mathrm{a}$. 

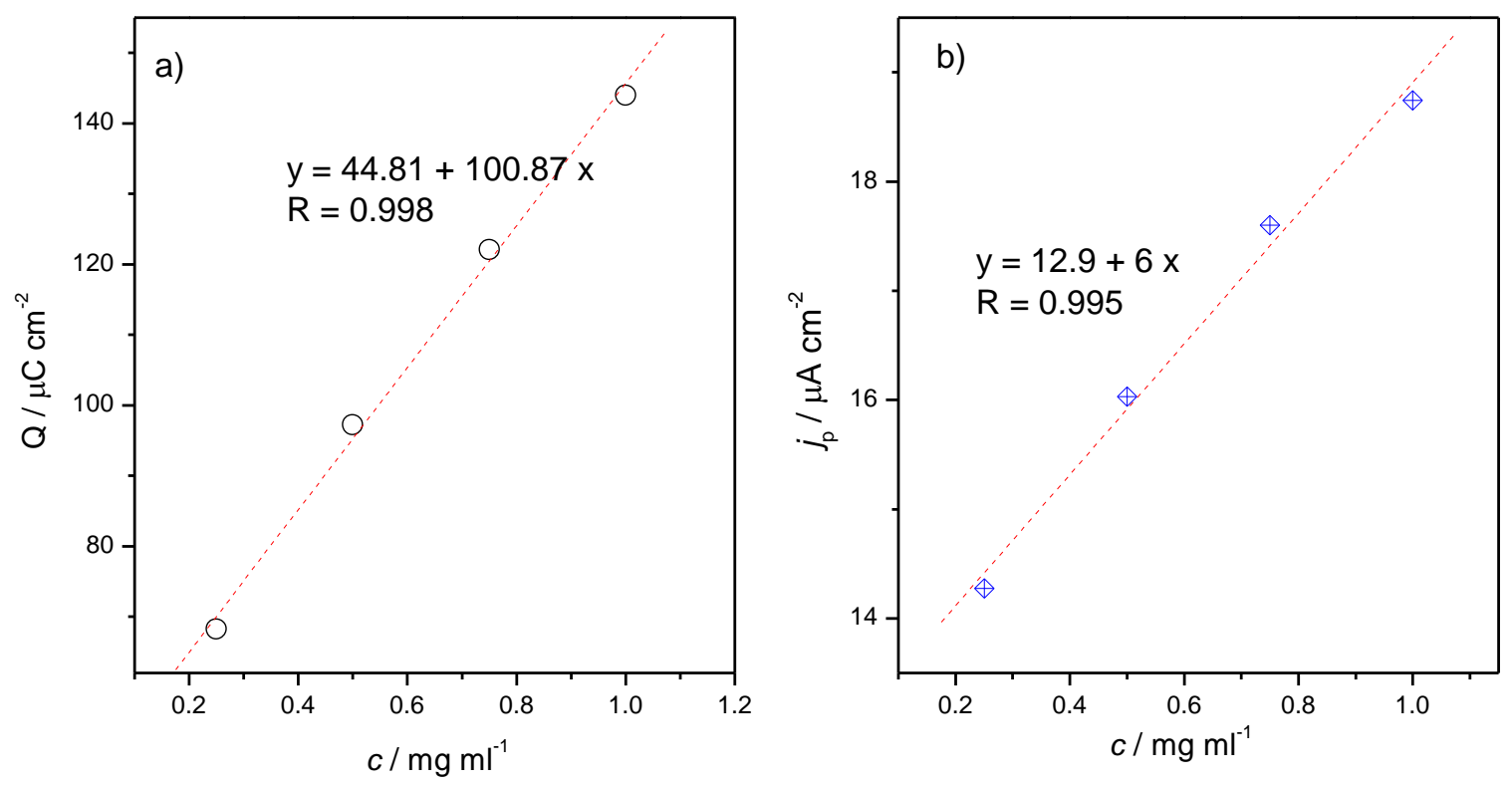

Figure 2. The dependency of charge (a) and peak current density (b) from concentration

As it can be noticed from Figures 1 and 2, highest $Q$ value was obtained for the most concentrated solution, which has larger amount of phenolic compounds. Similar value of $\mathrm{Q}$ was obtained by measuring human and horse plasma antioxidant activity applying CV on GC electrode [33]. The other electrochemical parameter that was analysed is peak current density (jp) and its dependency from concentration as is presented in Figure 2b. In addition, it can be noticed that significant and high linear correlations were found for jp and $\mathrm{Q}$ from concentration.

The results obtained by CV measurements are consistent with total phenolic and flavonoid contents and with spectrophotometric antioxidant assay (DPPH test) which confirms the same high antioxidant activity (Table 1) in both, methanolic and aqueous extracts of dark red corn. Other authors presented positive correlation between results obtained by tested methods, electrochemical and biochemical [34, 35]. In comparison to these published data, our results show up to 10 times higher electrochemical responses than some wild, polyphenolic rich medicinal plants. When it comes to spectrophotometrical methods and antioxidant capacity, earlier studies reported that red maize grain extracts had high antioxidant activity, from 20-60\% higher than Trolox which is standard antioxidant [36]. According to other references [37-40], dark colored maze grains have 3.5-, 4.6-, 4.5-, 7.3-, 28-times and 100.9-times lower antioxidant capacity than lemon, orange, red sorghum, black sorghum, blueberry and green tea, respectively. When compared to available literature [36, 38, 41], total polyphenolic content was similar or higher than our data (approx. $2 \mathrm{mg} \mathrm{g}^{-1}$ ). The same was found for total anthocyanin content which were $0.5 \mathrm{mg} \mathrm{g}^{-1}$ in red maize cultivars and $0.2 \mathrm{mg} \mathrm{g}^{-1}$ in blue, in average $[36,41]$.

Table 1. Total contents of tested biochemical parameters and antioxidant capacity of dark red corn grains $(\bar{X} \pm \mathrm{Se})$

\begin{tabular}{cc}
\hline Content & Dark red corn grain $(\mathbf{d w})$ \\
\hline Total sugars $\left(\mathrm{mg} \mathrm{g}^{-1}\right)$ & $155.29 \pm 2.55$ \\
Total carotenoids $\left(\mathrm{mg} \mathrm{g}^{-1}\right)$ & $10.30 \pm 2.7$ \\
Total polyphenolics $\left(\mathrm{mg} \mathrm{g}^{-1}\right)$ & $1.1 \pm 0.23$ \\
Total flavonoids $\left(\mathrm{mg} \mathrm{g}^{-1}\right)$ & $0.1 \pm 0.12$ \\
Total anthocyanidins $\left(\mathrm{mg} \mathrm{g}^{-1}\right)$ & $0.37 \pm 0.14$ \\
DPPH-test $(\%$ of inhibition) of & $83.59 \pm 3.21 / 83.41 \pm 5.93$ \\
MeOH/aqueous extract & \\
\hline
\end{tabular}

General biochemical properties and quality parameters of tested dark red corn seeds are presented in Tables 1-2. The major anthocyanins compounds in dark red corn seeds are cyanidin and peonidin, 
followed with quercetin (flavonol) and apigenin (flavone) derivatives (Tables 2 and 3). Results from previously reported data confirmed high and dose-dependent DPPH-scavenging capacity of mentioned compounds, as well as carotenoids which are potent natural antioxidants. But it was shown that presence of certain antioxidants do not represent their total antioxidant capacity due to the interactions among the antioxidant compounds in a food mixture [42, 43].

Table 2. Individual polyphenolic compounds in dark red corn grains $(\bar{X} \pm \mathrm{Se})$

\begin{tabular}{ccccc}
\hline & $\mathbf{M}^{-}(\mathrm{m} / z)$ & $\mathbf{M S}^{\mathbf{n}}(\mathrm{m} / \mathrm{z})$ & Tentative identification & $\mathbf{M g ~ g}^{-\mathbf{1}} \mathbf{d w}$ \\
\hline 1 & 625 & 463,301 & quercetin 3,4'-O-diglucoside & $7.45 \pm 0.99$ \\
2 & 507 & 285 & phloretin 3',5'-Di-C-glucoside & $23.57 \pm 3.36$ \\
3 & 595 & $503,474,354$ & $\begin{array}{c}\text { apigenin-6,8-di-C-glucoside (vicenin-2) } 1 \\
\text { luteolin-(6-C-pentosyl)-8-C- } \beta \text {-D- }\end{array}$ & $21.31 \pm 2.63$ \\
4 & 579 & $489,459,399,369$ & glucopyranoside & $8.47 \pm 1.01$ \\
5 & 624 & $503,383,533$ & apigenin-6,8-di-C-glucoside (vicenin-2) 2 & $8.50 \pm 1.39$ \\
6 & 505 & 301 & quercetin-3-O-glucose-6"-acetate & $46.25 \pm 7.26$ \\
7 & 563 & $473,443,503,454,564,353$, & apigenin-6,8-di-C-glucoside (vicenin-2) 3 & $6.65 \pm 1.22$ \\
8 & 593 & 384 & & \\
9 & 533 & $503,473,383$ & vicenin 4 & $4.37 \pm 0.85$ \\
10 & 577 & $473,443,353$ & apigenin 6,8-di-C-pentoside & $3.40 \pm 0.31$ \\
11 & 609 & $457,413,353,293,473,503$ & apigenin-8-C-hexoside-rhamnoside & $25.97 \pm 4.56$ \\
12 & 463 & 301 & quercetin 7-rutinoside & $7.36 \pm 0.90$ \\
13 & 463 & 301 & quercetin-3-galactoside & $22.29 \pm 4.24$ \\
14 & 623 & 301 & quercetin-3-glucoside & $14.06 \pm 2.17$ \\
15 & 477 & 315 & isorhamnetin-3-O-rutinoside & $22.22 \pm 3.37$ \\
\hline
\end{tabular}

Table 3. Individual anthocyanin derivatives in dark red corn grains $(\bar{X} \pm \mathrm{Se})$

\begin{tabular}{ccccc}
\hline & $\mathbf{M +}(\mathrm{m} / \mathrm{z})$ & $\mathbf{M S}^{\mathbf{n}}(\mathrm{m} / \mathrm{z})$ & Tentative identification & $\boldsymbol{\mu g ~ g}^{\mathbf{- 1}} \mathbf{d w}$ \\
\hline 1 & 493 & 449,287 & cyanidin-3-O-glucoside & $82.63 \pm 8.86$ \\
2 & 463 & 301 & peonidin-3-O-glucoside & $36.79 \pm 4.82$ \\
3 & 535 & 287 & cyanidin-3-(6'-malonyl-hexoside) 1 & $37.20 \pm 5.74$ \\
4 & 535 & 287 & cyanidin-3-(6'-malonyl-hexoside) 2 & $145.19 \pm 21.27$ \\
5 & 549 & 301 & peonidin-3-O-(6"-malonyl-hexoside) 1 & $13.55 \pm 1.89$ \\
6 & 549 & 301 & peonidin-3-O-(6"-malonyl-hexoside) 2 & $55.31 \pm 8.42$ \\
7 & 621 & 287 & cyanidin-3-O-(3",6"-O-dimalonyl-glucoside) & $32.68 \pm 4.85$ \\
\hline
\end{tabular}

Figure 3 represents the effect of the potential scan rate on the voltammetric response for the oxidation of red corn pigments and was investigated in the range of $20-160 \mathrm{mV} \mathrm{s}^{-1}$. The anodic peak current varied linearly with the square root of the scan rate (inset of Figure 3), indicating that the oxidation of red corn pigments was controlled by diffusion to the electrode surface. 


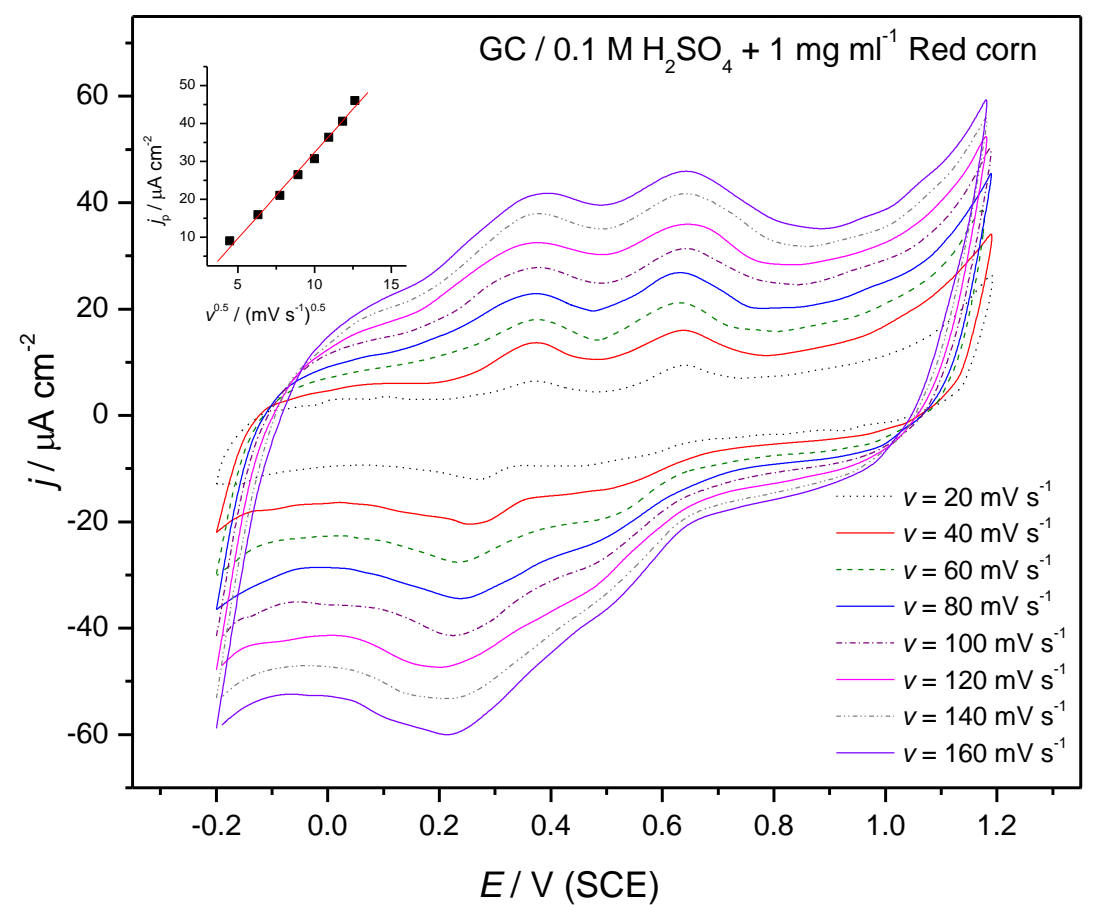

Figure 3. CVs of $1 \mathrm{mg} \mathrm{mlL}^{-1}$ dark red corn seeds extract obtained for scan rates $20-160 \mathrm{mV} \mathrm{s}^{-1}$. Insert shows the linear plot of anodic peak currents versus square root of scan rate.

Since the corrosion process in its most common sense is oxidation of metal in reaction with oxidant, the voltammetric response for the oxidation of red corn pigments indicated that it could be employed as a corrosion inhibitor.

The corrosion inhibiting effect was examined in acidic solution at $p \mathrm{H}$ value at which the highest activity of investigated pigments is previously observed. To assess the inhibiting effect, the polarization resistance $(\mathrm{Rp})$ was determined as a slope of the potential versus current curve from LPR data after measurement in the potentials range of $-0.01 \mathrm{~V}-0.01 \mathrm{~V}$ relative to Eoc. Afterwards, the corrosion inhibition efficiency, $\eta_{\text {inh }}$, was calculated according to equation:

$$
\eta_{\text {inh }}=\left(1-\frac{R_{p, M e}}{R_{p, \text { inh }}}\right) * 100
$$

Here, $R_{P, M e}$ and $R_{P, i n h}$ are determined values of polarization resistance $(R p)$ for a metal in the solution without and with inhibitor, respectively. The determined value of $\eta_{\text {inh }}$, presented in Table 4, may be considered also as anti-corrosion capacity of a solution containing red corn pigment in contact with a mild steel. Although it is known that mild steels have poor corrosion resistance, they are still widely used in many applications. It is important to find possible alternatives to aggressive, toxic and harmful chemicals, which are now used for its corrosion protection.

Table 4. Determined corrosion inhibition efficiency of examined red corn pigments on a mild steel

\begin{tabular}{ccccccc}
\hline concentration $/ \mathbf{g ~ m l}^{\mathbf{1}}$ & 0 & 0.4 & 0.8 & 1.2 & 1.6 & 2.0 \\
\hline $\boldsymbol{\eta}_{\text {inh }} / \boldsymbol{\%}$ & - & 29.6 & 33.3 & 55.4 & 58.7 & 68.9 \\
\hline
\end{tabular}

Without detailed mechanism of corrosion inhibition analysis, it is evident that the inhibiting effect increases with increase in red corn pigments concentration. It is proven that organic molecules preferably adsorb on metal surfaces [14]. Upon consideration of CV of red corn pigments, obtaining the higher currents for cathodic and anodic peaks for the same scan rate, indicates the decreasing of the 
diffusion layer, i.e. the quasi-reversibility. This also can indicate that the transfer of electrons takes place via substances absorbed at surface [44]. It must be noted that it is not unambiguously known which active component of the plant extract inhibits the corrosion to the greatest extent. Usually, a mixture of components give better corrosion inhibiting effect than any of those components solely, similar to antioxidant properties above mentioned.

To our best knowledge, the inhibitive effect of red corn have not been investigated before, but it is reported that corn silk extracts have inhibitive effect in the range of $66-95 \%$ in acidic media for mild steel, what is higher than red corn [45]. Abbasov et.al reported corrosion inhibition of mild steel using surfactants obtained from corn oil, which is based on fatty acids [46]. Attained inhibitive effect ranged from 80 to $99 \%$. Comparing to this, the red corn has low to moderate inhibiting effect. The common fact is that the corrosion inhibitive effect increased with inhibitor concentration.

\section{Conclusions}

Electrochemical and biochemical properties of dark red corn grains were investigated from the aspect of antiradical and anti-corrosion capacity. Electrochemical behavior of the red corn pigments was examined by $\mathrm{CV}$ and the electrochemical oxidation of tested compounds was presented by two peaks, both in forward and the backward scan, indicating a quasi-reversible process typical for the oxidation of phenols or hydroquinones. The quantity of antioxidants was determined from the charge under the anodic peaks. The results obtained by CV measurements are in accordance with total phenolic and flavonoid contents and with spectrophotometric antioxidant assay confirming high antioxidant activity (83\%). Biochemical investigations revealed that the major anthocyanins compounds in dark red corn seeds are cyanidin and peonidin, followed with quercetin and apigenin derivatives. The obtained antioxidant activity of polyphenolics was accompanied with the corrosion inhibiting examination. The linear polarization resistance measurements on mild steel were performed for examining the corrosion inhibitive behavior and the corrosion inhibiting effect of dark red corn grains was established by calculating the corrosion inhibition efficiency ranged from 30 to $70 \%$.

Acknowledgements. This work was supported by the Ministry of Education, Science and Technological Development of the Republic of Serbia (Grant No. 451-03-68/2020-14/200026).

\section{References}

1. BUNACIU, A.A., DANET, A. F., FLESCHIN, S., ABOUL -ENEIN, H. Y., Recent Applications for in Vitro Antioxidant Activity Assay, Crit. Rev. Anal. Chem., 46, no. 5, 2016, p. 389.

2. PISOSCHI, A.M., CIMPEANU C., PREDOI, G., Electrochemical Methods for Total Antioxidant Capacity and its Main Contributors Determination: A review, Open Chem., 13, no. 1, 2015, p. 824.

3. SAMRA, M. A., CHADEA, V. S., ECONOMOU, A., CALOKERINOS, A. KEFAlAS, P., Antioxidant/prooxidant properties of model phenolic compounds: Part I. Studies on equimolar mixtures by chemiluminescence and cyclic voltammetry, Food Chem. 125, 2011, p. 622.

4. DAVID, M., SERBAN, A., RADUlESCU, C., DANET, A. F., FLORESCU, M., Bioelectrochemical evaluation of plant extracts and gold nanozymebased sensors for total antioxidant capacity determination, Bioelectrochemistry, 129, 2019, p. 124.

5. ŽILIĆ, S., SERPEN, A., AKILliOGLU, G., GOKMEN, V., VANČETOVIĆ, J., Phenolic Compounds, Carotenoids, Anthocyanins, and Antioxidant Capacity of Colored Maize (Zea maysL.) Kernels, J. Agric.Food Chem., 60, 2012, p. 1224.

6. CAPOCCHI, A., BOTTEGA, S., SPANO, C., FONTANINI, D., Phytochemicals and antioxidant capacity in four Italian traditional maize (Zea mays L.) varieties, Int. J. Food Sci. Nutr., 68, no. 5, 2017, p. 515.

7.de LIMA, A.A., SUSSUCHI, E.M., De GIOVANI, W.F., Electrochemical and Antioxidant Properties of Anthocyanins and Anthocyanidins, Croat. Chem. Acta, 80, no. 1, 2007, p. 29. 
8.SATUE-GRACIA, M.T., HEINONEN, M.T., FRANKEL, E.N., Anthocyanins as Antioxidants on Human Low-Density Lipoprotein and Lecithin-Liposome Systems, J. Agric. Food Chem., 45, no. 9, 1997, p. 3362.

9.HANGANU, D., KINGA OLAH, N., MOCAN, A., VLASE, L., BENEDEC, D., RAITA, O., CRINA TOMA, C., Comparative Polyphenolic Content and Antioxidant Activities of Two Romanian Lysimachia Species, Rev. Chim., 67(2), 2016, p 227.

10. MONCADA, M.C., de MEQUITA, M.F., dos SANTOS, M.M.C., Electrochemical oxidation of the synthetic anthocyanin analogue 4-methyl-7,8-dihydroxyflavylium salt, J. Electroanal. Chem., 636, no.1-2, 2009, p. 60.

11.YANG, B., KOTANI, A., ARAI, K., KUSU, F., Estimation of the Antioxidant Activities of Flavonoids from Their Oxidation Potentials, Anal. Sci., 7, no. 5, 2001, p. 599.

12.ZHANG, D., CHU, L., LIU, Y., WANG, A., JI, B., WU, W., ZHOU, F., WEI, Y., CHENG, Q., CAI, S., XIE, L., JIA, G., Analysis of the Antioxidant Capacities of Flavonoids under Different Spectrophotometric Assays Using Cyclic Voltammetry and Density Functional Theory, J. Agric. Food Chem., 59, no. 18, 2011, p._10277.

13.SOCHOR, J., DOBES, J., KRYSTOFOVA, O., RUTTKAY-NEDECKY, B., BABULA, P., POHANKA, M., JURIKOVA, T., ZITKA, O., ADAM, V., KLEJDUS, B., KIZEK, R., Electrochemistry as a Tool for Studying Antioxidant Properties. Int. J. Electrochem. Sci., 8, 2013, p. 8464.

14.MARZORATI, S., VEROTTA, L., TRASATTI, S.P., Green Corrosion Inhibitors from Natural Sources and Biomass Wastes, Molecules, 24, no.1, 2019, p.48.

15.PRABAKARAN, M., KIM, S.H., VENKATESAN, H., CHUNG, I.M., Evaluation of Antioxidant and Anticorrosion Properties of Epipremnum aureum, J. Ind. Eng. Chem., 37, 2016, p. 47.

16. MAGNI, M., POSTIGLIONE, E., MARZORATI, S., VEROTTA, L., TRASATTI, S., Green Corrosion Inhibitors from Agri-Food Wastes: The Case of Punica granatum Extract and Its Constituent Ellagic Acid. A Validation Study, Processes, 8, no. 3, 2020, p. 272.

17.OSTOVARI, A., HOSEINIEH, S. M., PEIKARI, M., SHADIZADEH, S. R., HASHEMI, S.J., Corrosion inhibition of mild steel in $1 \mathrm{M} \mathrm{HCl}$ solution by henna extract: A comparative study of the inhibition by henna and its constituents (Lawsone, Gallic acid, a-D-Glucose and Tannic acid), Corros. Sci., 51, 2009, p. 1935.

18.OBOT, I.B., MADHANKUMAR, A., Enhanced corrosion inhibition effect of tannic acid in the presence of gallic acid at mild steel/HCl acid solution interface, J. Ind. Eng. Chem., 25, 2015, p. 105.

19.AACC, International Approved Methods of Analysis. AACCI Method 80-60.01 Determination of Reducing and Nonreducing Sugars, $11^{\text {th }}$ Ed., St. Paul, MN, 1978.

20. de CARVALHO, L.M.J., GOMES, P.B., de OLIVIERA, R., GODOY, R.L., PACHECO, S., do MONTE, P.H.F., de CARVALHO, J.L.V., NUTTI, M.R., NEVES, A.C.L., VIEIRA, A.C., RAMOS, S.R.R., Total carotenoid content, $\alpha$-carotene and $\beta$-carotene, of landrace pumpkins (Cucurbita moschata Duch): A preliminary study, Food Res. Int., 47, no. 2, 2012, p.337.

21.MAKKAR, H.P,S., Quantification of tannins in tree and shrub foliage: A laboratory manual, Springer Netherlands, 2003, p. 49.

22.PEKAL, A., PYRZYNSKA, K., Application of free radical diphenylpicrylhydrazyl (DPPH) to estimate the antioxidant capacity of food samples, Food Anal. Methods, 7, no. 9, 2014, p. 1776.

23.LEE, J., DURST, R.W., WROLSTAD, R.E., Determination of total monomeric anthocyanin pigment content of fruit juices, beverages, natural colorants and wines by the $\mathrm{pH}$ differential method: collaborative study. J. AOAC Int., 88, no. 5, 2005, p.1269.

24.KIPROVSKI, B., ĐALOVIĆ, I., ADAMOVIĆ, D., MITROVIĆ, P., MARJANOVIĆ-JEROMELA, A., MALENČIĆ, Đ., POPOVIĆ, T., Biochemical changes in Oenothera biennis plants infected by 'Candidatus Phytoplasma solani', J. Plant Pathol., 100, no. 2, 2018, p. 209. 
25.PANDA, S.K., Assay guided comparison for enzymatic and non-enzymatic antioxidant activities with special reference to medicinal plants. Antioxidant Enzyme, 14, 2012, p.382.

26.WANG, S.Y., ZHENG, W., GALLETTA, G.J., Cultural System Affects Fruit Quality and Antioxidant Capacity in Strawberries, J. Agric. Food Chem., 50, no. 22, 2002, p. 6534.

27.KIPROVSKI, B., BORKOVIĆ, B., MALENČIĆ, Đ., VEBERIČ, R., ŠTAMPAR, F. AND MIKULIČ-PETKOVŠEK, M., Postharvest changes in primary and secondary metabolites of sweet cherry cultivars induced by Monilinia laxa, Postharvest Biol. Tech., 144, 2018, p. 46.

28. REBELO, M.J., REGO, R., FERREIRA, M., OLIVEIRA, M.C., Comparative study of the antioxidant capacity and polyphenol content of Douro wines by chemical and electrochemical methods, Food Chem. 141, no. 1, 2013, p. 566.

29. SOUZA, L.P., CALEGARI, F., ZARBIN, A.J.G., MARCOLINO-JUNIOR, L.H., BERGAMINI, M.F., Voltammetric Determination of the Antioxidant Capacity in Wine

Samples Using a Carbon Nanotube Modified Electrode, J. Agric. Food Chem., 59, no. 14, 2011, p. 7620.

30. LUND, H., HAMMERICH, O., Organic Electrochemistry. $4^{\text {th }}$ ed., Marcel Dekker, New York, 2001, p.499.

31.YAKOVLEVA, K.E., KURZEEV, S.A., STEPANOVA, E.V., FEDOROVA, T.V., KUZNETSOV, B.A., KOROLEVA, O.V., Characterization of Plant Phenolic Compounds by Cyclic Voltammetry, Appl. Biochem. Microbiol. 43, no. 6, 2007, p. 661.

32.KIlMARTIN, P.A., ZOY, H., WATERHOUSE, A.L., Correlation of Wine Phenolic Composition versus Cyclic Voltammetry Response, Am. J. Enol. Vitic. 53, 2002, p. 294.

33.MARTINEZ, S., VALEK, L., RESETIC, J., FERENC RUZIC, D., Cyclic voltammetry study of plasma antioxidant capacity - Comparison with the DPPH and TAS spectrophotometric methods, J. Electroanal. Chem., 588, no. 1, 2006, p. 68.

34.BARros, L., CABritA, L., BOAS, M.V., CARVAlHO, A.M., FERREIRA, I.C., Chemical, biochemical and electrochemical assays to evaluate phytochemicals and antioxidant activity of wild plants, Food Chem., 127, no. 4, 2011, p. 1600.

35.HOYOS-ARBELAEZ, J., VAZQUEZ, M., CONTRERAS - CALDERON, Electrochemical methods as a tool for determining the antioxidant capacity of food and beverages: A review, Food Chem., 221, 2017, p. 1371.

36. LOPEZ-MARTINEZ, L.X., PARKIN, K.L., GARCIA, H. S., Phase II-inducing, polyphenols content and antioxidant capacity of corn (Zea mays L.) from phenotypes of white, blue, red and purple colors processed into masa and tortillas, Plant Food Hum. Nutr., 66, no. 1, 2011, p. 41.

37. DEL POSO- INSFRAN, D., BRENES, C. H., SALDIVAR, S.O.S., CALCOTT, S.T., Polyphenolic and antioxidant content of white and blue corn (Zea mays L.) products, Food. Res. Int., 39, no. 6, 2006, p. 696.

38. DYKES, L., ROONEY, L.W., Phenolic compounds in cereal grains and their healt benefits, Cereal Food World, 52, no. 3, 2007, p. 105.

39.TULIN, A. O., KAFKAS, E., OZCAH, H., Biochemical analysis with measurements of bioactive ingredients of lemon varieties, Journal on Processing and Energy in Agriculture, 21, no. 3, 2017, p. 146.

40. ZHAO, C. N., TANG, G. Y., CAO, C. Y., XU, X. Y., GAN, R. Y., LIU, Q, MAO, Q.Q., SHANG, A., LI, H.B., Phenolic Profiles and Antioxidant Activities of 30 Tea Infusions from Green, Black, Oolong, White, Yellow and Dark Teas, Antioxidants, 8, no.7, 2019, p.215.

41. ABDEL AAL, E. S. M., YOUNG, J.C., RABALSKI, I., Anthocyanin Composition in Black, Blue, Pink, Purple, and Red Cereal Grains, J. Agr. Food Chem., 54, no. 13, 2006, p. 4696.

42. MAGALHAES, L.M., SEGUNDO, M.A., REIS, S., LIMA, J.L., Methodological aspects about in vitro evaluation of antioxidant properties, Anal. Chim. Acta, 613, no. 1, 2008, p. 1. 
43.BACCHETTI, T., MASCIANGElO, S., MICHELETTI, A., FERRETTI, G., Carotenoids, Phenolic Compounds and Antioxidant Capacity of Five Local Italian Corn (Zea Mays L.) Kernels, J. Nutr. Food Sci., 3, 2013, p. 1.

44.CHANDRABHAN, V., EBENSO, E.E., BAHANDUR, I., QURAISHI, M.A., An overview on plant extracts as environmental sustainable and green corrosion inhibitors for metals and alloys in aggressive corrosive media, J. Mol. Liq., 266, 2018, p. 577.

45.AYAH, E., ORUBITE - OKOROSAYE, K., JAMES, A., Methanolic and Aqueous Extracts of Corn Silk as Corrosion Inhibitor for Mild Steel in Hydrochloric Acid at Different Temperatures, J. Appl. Sci. Environ. Manage., 22, no. 3, 2018, p. 439.

46. ABBASOV, V. M., Abd El-LATEEF, H., M., ALIYEVA, L.I., QASIMOV, E.E., ISMAYLOV, I.T. KHALAF, M. M., A study of the corrosion inhibition of mild steel $\mathrm{C} 1018$ in $\mathrm{CO}_{2}$-saturated brine using some novel surfactants based on corn oil, Egyptian Journal of Petroleum, 22, 2013, p. 451.

$\overline{\text { Manuscript received: } 10.12 .2019}$ 